\title{
Increasing detail of distributed runoff modeling using fuzzy logic in curve number
}

\author{
Runkui Li $\cdot$ Xiaoping Rui $\cdot$ A-Xing Zhu \\ Junzhi Liu $\cdot$ Lawrence E. Band $\cdot$ Xianfeng Song
}

Received: 12 November 2013/Accepted: 14 August 2014/Published online: 9 September 2014

(C) Springer-Verlag Berlin Heidelberg 2014

\begin{abstract}
The Soil Conservation Service Curve Number runoff model is widely used in runoff prediction and has been incorporated into many software packages for watershed modeling. The Curve Number $(\mathrm{CN})$ is the key parameter in the model, but it is largely dependent on Hydrologic Soil Group (HSG) classifications which may induce aggregation of detailed soil information. However, little attention and efforts have been paid to reduce such aggregation effect for retaining those valuable soil information to derive more detailed $\mathrm{CN}$. This study proposed to integrate fuzzy logic to derive detailed CN. Membership of a given soil to each HSG is first calculated based on soil properties and HSG classification criteria; then, detailed
\end{abstract}

R. Li $\cdot$ X. Rui $\cdot$ X. Song $(\bowtie)$

College of Resources and Environment, University of Chinese Academy of Sciences, Beijing 100049, China

e-mail: song.osgeo@gmail.com

R. Li

e-mail: lirk@ucas.ac.cn

A.-X. Zhu · J. Liu

School of Geography, Nanjing Normal University,

Nanjing 210023, China

A.-X. Zhu · L. E. Band

State Key Lab of Resources and Environmental Information System, Institute of Geographical Sciences and Natural Resources Research, Chinese Academy of Sciences, Beijing 100101, China

A.-X. Zhu

Department of Geography, University of Wisconsin-Madison, 550 North Park Street, Madison, WI 53706, USA

L. E. Band

Department of Geography, University of North Carolina at Chapel Hill, Chapel Hill, NC 27599, USA and continuous $\mathrm{CN}$ is derived using the membership as weight for $\mathrm{CN}$ of each soil-cover complex. The proposed approach was incorporated into an automation system and its further effects on runoff modeling were examined. A case study shows fuzzy $\mathrm{CN}$ possesses more spatial details and leads to obvious spatial differences of simulated runoff. The developed system could also be used to detect inconsistency of HSG placements.

Keywords Runoff curve number - Hydrologic soil group · Fuzzy logic - Soil and water assessment tool $($ SWAT $) \cdot$ Distributed hydrological modeling

\section{Introduction}

The Soil Conservation Service Curve Number (SCS-CN) runoff model (Soil Conservation Service 1972) is widely used in surface runoff modeling for various areas and has been incorporated into many popular hydrologic software packages (Young and Carleton 2006; Mishra et al. 2008; Elhakeem and Papanicolaou 2009). In practical work, the derivation of $\mathrm{CN}$ is usually accomplished via look-up table given by National Engineering Handbook for each hydrologic soil-cover complex (USDA 2004), e.g., combination of hydrologic soil group (HSG), land use, and treatment class. Theoretical $\mathrm{CN}$ value falls in the range of $0-100$, but practical design values validated by experiences, are more likely to be between 40 and 98, with few exceptions (Van Mullem 1991). As a result, the SCS-CN model is extremely sensitive to $\mathrm{CN}$ parameter with a relative narrow range (Ponce and Hawkins 1996). And slight drifting in CN would lead to a significant difference in runoff model simulation. Therefore, $\mathrm{CN}$ determination is a key procedure during runoff modeling. 
One of the major influencing factors over $\mathrm{CN}$ is the HSG assignment of soils (Shirmohammadi et al. 1997; USDA 2004). About 14,000 types of soils had been identified in the United States (McCuen 2004), and were assigned into four HSGs (A, B, C, and D) according to soil permeability (Musgrave 1955). Under given surface conditions, a certain representative $\mathrm{CN}$ value is assigned to an $\mathrm{HSG}$ and $\mathrm{CNs}$ for different HSGs vary largely. Therefore, HSG classification is critical for the derived $\mathrm{CN}$ and the predicted runoff.

HSG assignment greatly facilitates the application of SCS-CN model, but potentially raises two issues need to be concerned about:

1. Aggregation effect on detailed soil information. Soils usually vary gradually in property domain and space domain (Zhu 1997), but these soils are classified into various soil types and further aggregated into four HSGs during soil survey. HSGs are classified based on soil hydrologic characteristics, such as soil water permeability, to represent levels of runoff potential, labeled with increasing potential from A, B, C, to D. Assigning various soils to four HSGs may induce two aspects of uncertainty: (a) soils having different hydrologic attributes would likely be designated to the same HSG, thus the final HSG mutes the differences among original soils; (b) Similar soils close to the bounds of HSG may be assigned to neighboring different HSGs and the small differences between original soils would be exaggerated (Mark and Csillag 1989; Zhu 1997); this will lead to a big jump of CN. For example, HSGs A, B, C, and D combining with woodlands at good hydrologic condition would have $\mathrm{CN}$ of $30,55,70$, and 77 , respectively, which means difference of $\mathrm{CN}$ between the neighboring HSGs would be up to 25 (between group A and B). Therefore, HSG classification may cause sudden jumps of $\mathrm{CN}$ by assigning similar soils into different HSGs, otherwise will erase the influence of soil difference on $\mathrm{CN}$ by assigning different soils to the same HSG. Such aggregation effect of HSG on soil information has been verified by previous studies, and its subsequent influence on watershed modeling has also been discussed (Ye et al. 2011; Li et al. 2012).

2. Inappropriate HSG placement. Only some initial groupings within selected small watersheds were conducted based on rainfall-runoff data and infiltrometer plots, and most soils were actually assigned to the corresponding HSGs based on soil scientists' interpretation of the published criteria (Soil Survey Division Staff 1993). As the interpretation has varied through time and across states and regions, HSG classification criteria is not uniformly applied over the United States, which may cause improper placements of soils into
HSGs. This situation mostly occurs when comparing soils with similar hydrologic and physical properties but different hydrologic group placement (Nielson and Hjelmfelt 1998; Hjelmfelt et al. 2001; Van Mullem et al. 2002).

Though the issues above have drawn wide attention, few effective solutions have yet been raised. A joint work group was formed in 1990 by the US Department of Agriculture, with the principal aim of reconsidering the hydrologic soil classification after recognizing the vastly expanded database and the capabilities of modern computers (Van Mullem et al. 2002). The research group developed a rule based on automated fuzzy system to reduce the errors associated with soil scientists' interpretation of the HSG criteria (Nielson and Hjelmfelt 1998). However, classification of group $\mathrm{B}$ and $\mathrm{C}$ is difficult and finally leads to misclassification. The reason was attributed to the fact that a given soil may not be fitted entirely into a single HSG.

For this reason, an improved method taking advantage of detailed soil information from soil database to derive finer HSG classification and $\mathrm{CN}$ is clearly needed. Distributed watershed modeling highlights the spatial distribution of modeling results, but such spatial detail would probably be obscured due to aggregation effect of HSG on detailed soil information. Meanwhile, there has been a significant accumulation in basic soil attribute data since the initial classification of HSG in the 1950s (Musgrave 1955), and this will greatly facilitate the refining of HSG. The purpose of this study is: (1) to develop an automated system based on detailed soil attribute data to mitigate the aggregation effect of $\mathrm{HSG}$ on $\mathrm{CN}$, (2) to examine the misplacement of HSG, and (3) to investigate the potential effects of the proposed approach on the derived $\mathrm{CN}$ and the modeled runoff.

\section{Materials and methods}

\section{SCS-CN model}

The SCS-CN runoff equation is an empirical model that consists of water balance equations and two fundamental hypotheses (Mishra et al. 2006) expressed as:

$P=I_{\mathrm{a}}+F+Q$

$\frac{Q}{P-I_{\mathrm{a}}}=\frac{F}{S}$

$I_{\mathrm{a}}=\lambda S$

where $P=$ total rainfall depth $(\mathrm{mm}), I_{\mathrm{a}}=$ initial abstraction $(\mathrm{mm}), F=$ cumulative infiltration $(\mathrm{mm}), Q=$ direct runoff $(\mathrm{mm})$, and $S=$ potential maximum retention $(\mathrm{mm})$. 


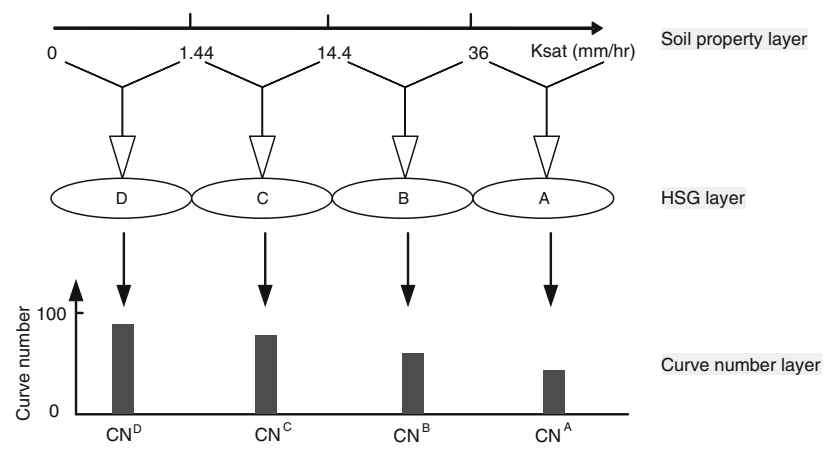

Fig. 1 Procedure from soil physical property to HSG and CN

The initial abstraction, $I_{\mathrm{a}}$, is commonly appropriated as $0.2 S(\lambda \approx 0.2)$. A combination of (1), (2), and (3) leads to the popular form of SCS-CN model:

$Q=\frac{(P-0.2 S)^{2}}{P+0.8 S}$

$S$ can be transformed to $\mathrm{CN}$ scale using the following relation:

$S=25.4\left(\frac{1000}{\mathrm{CN}}-10\right)$

where $\mathrm{CN}=$ curve number. For a given rainfall $(P>0.2 S)$, higher $\mathrm{CN}$ generates more runoff.

Typical $\mathrm{CN}$ for medium antecedent moisture condition (AMC II), usually labeled as CN2, is provided by SCS Engineering Division for each HSG for practical use (Ponce and Hawkins 1996; USDA 2004). The transformation of $\mathrm{CN} 2$ to other moisture conditions (AMC I and AMC III) can be accomplished with several conversion formula (Mishra et al. 2008). CN2 are given in the table for each of the four HSGs (A, B, C, and D), with group A standing for low runoff potential, group $B$ for moderate rate of infiltration, group $\mathrm{C}$ for slow rate of infiltration, and group D for high runoff potential, respectively (Fig. 1). USDA-NRCS Soil Survey Staff defines HSG as a group of soils that having similar runoff potential under similar storm and cover conditions (USDA 2007). Based on the classification procedure showed by Fig. 1, aggregation effect on detailed soil information can be observed. The aggregation would cause two kinds of uncertainty: (1) all types of soils will be simplified to four HSGs and many different soils will be put into the same group; the differences between original soils were omitted; and (2) some similar soils around the group boundary would be separated into different groups; the original small differences between those soils were exaggerated.

Soils were originally assigned to HSGs based on measured rainfall, runoff, and infiltrometer data (Musgrave

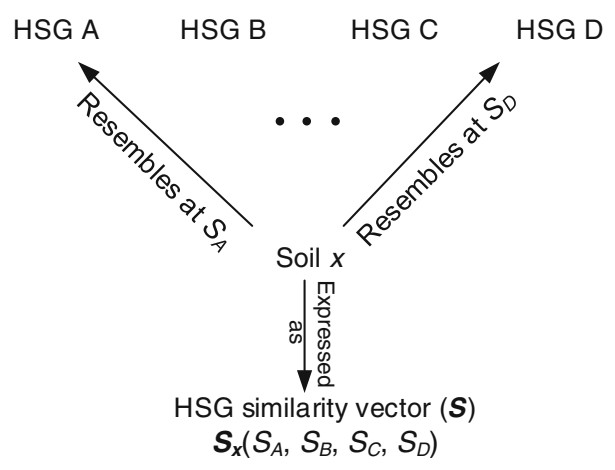

Fig. 2 Fuzzy representation of HSG using similarity vector

1955). HSG is determined according to saturated hydraulic conductivity of the least transmissive layer, and depth to water impermeable layer (dense and cemented horizon, such as a fragipan or duripan with saturated hydraulic conductivity $<0.1$ inches per hour) or depth to a phreatic water level (USDA 2007).

\section{Deriving CN from fuzzy HSG}

Soils are traditionally classified to the corresponding HSGs which are further used as surrogate of soil hydrologic information to derive $\mathrm{CN}$. Thus, the original soil attributes are aggregated by HSG assignment process (Fig. 1). To reduce the aggregation effect during this process, we proposed a fuzzy HSG concept to retain influence of detailed soil information on the derived fuzzy HSG and further on the $\mathrm{CN}$.

The proposed fuzzy HSG approach describes the relation between soils and existing HSGs based on fuzzy logic. Under fuzzy logic (Burrough 1989; Zhu 1997; Zhu et al. 1997, 2001), a soil can be assigned to more than one hydrologic group with different degrees of similarity. These degrees of similarity are referred to as fuzzy memberships. The fuzzy representation allows a soil to bear partial membership in each of the prescribed HSG. Each fuzzy membership is regarded as a similarity measure between the soil and the HSG. All fuzzy memberships are retained in this similarity representation (Fig. 2), which forms a four-element vector (HSG similarity vector, or fuzzy membership vector), $S_{x}\left(S_{\mathrm{A}}, S_{\mathrm{B}}, S_{\mathrm{C}}\right.$, and $\left.S_{\mathrm{D}}\right)$, where $S_{\mathrm{A}}$ in the vector represents the similarity of soil $x$ to soil hydrologic group A, ranging from 0 to $1 ; S_{\mathrm{B}}, S_{\mathrm{C}}$, and $S_{\mathrm{D}}$ represent similarity of soil $x$ to group $\mathrm{B}, \mathrm{C}$, and $\mathrm{D}$, so and so forth. In this way, a single soil type would no longer be approximated by individual HSG, but represented by multiple groups with varying memberships. Therefore, soils with small differences would be distinguished through their detailed memberships, and similar soils would possess similar memberships. 


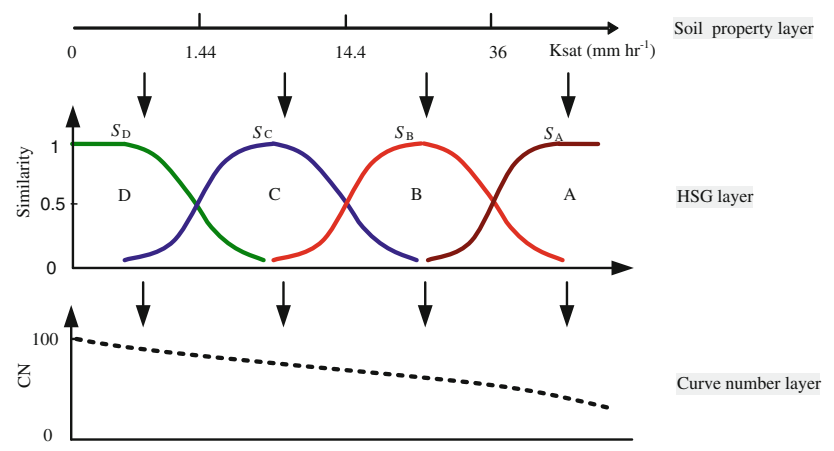

Fig. 3 Concept of representing continuous CN using fuzzy HSG with similarity vector

The proposed fuzzy HSG approach includes two steps: (1) the fuzzy memberships of a soil to all HSGs are calculated based on its hydrologic and physical properties; (2) the memberships are used as weights of the traditional CN2 values to compute the final $\mathrm{CN}$ for different conditions. In this way, the fuzzy logic method allows the soil-cover complexes to have intermediate $\mathrm{CN}$ other than only four levels of the traditional $\mathrm{CN}$.

The similarity between a soil and each HSG is essential. The process to derive similarity consists of three major parts (Fig. 3): (1) collect soil hydrologic information which is needed when assigning soil to HSG, including depth to a restrictive layer or phreatic water level and saturated hydrologic conductivity; (2) calculate the similarity of soil to each HSG using the fuzzy membership function, and (3) calculate fuzzy $\mathrm{CN}$ using a linear weighted method (the fuzzy memberships are used as weights of HSGs), with the incorporation of $\mathrm{CN}$ look-up tables to each soil-cover complexes. Soil-cover complexes will be assigned continuous CNs if their corresponding soil properties are similar. The fuzzy HSG approach largely circumvents the generalization of soil information caused by HSG assignment.

\section{Typical soil property value to $H S G$}

To calculate fuzzy HSG membership, the typical soil property values for each HSG must be defined. Based on the criteria of NEH, HSG covers a wide range of soil hydrologic attributes (USDA 2007). For example, a group $\mathrm{C}$ soil with a depth to water impermeable layer larger than $100 \mathrm{~cm}$ would have a wide range of saturated hydraulic conductivity of the least transmissive layer $\left(K_{\mathrm{MINsat}}\right)$ from 1.44 to $14.4 \mathrm{~mm} / \mathrm{h}$ (Fig. 4). As soil hydrologic properties generally follow an approximate logarithmic normal distribution (Schaap et al. 2001; Zhai and Benson 2006), soil saturated hydraulic conductivity was transformed to logarithmic value at the beginning. For the HSGs with two boundaries (e.g., group $\mathrm{B}$ and $\mathrm{C}$ ), the mean values of

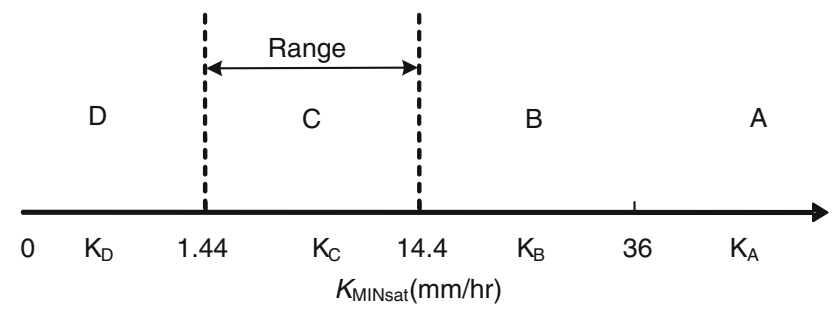

Fig. 4 Sketch showing the range and typical value for each HSG. $K_{\mathrm{A}}$, $K_{\mathrm{B}}, K_{\mathrm{C}}$, and $K_{\mathrm{D}}$-typical $K_{\mathrm{MINsat}}$ for soils A, B, C, and D, respectively

$K_{\text {MINsat }}$ were used as the typical values. While typical values for the single bounded group A and D were defined by an incremental to the bound of neighboring group (Fig. 4). Then the range and typical $K_{\text {MINsat }}$ for each HSG could be defined (Table 1). The typical value and range of each HSG was later fed into the fuzzy membership function to calculate the fuzzy membership of a given soil to each HSG.

\section{Calculating fuzzy membership of HSGs}

Fuzzy membership functions were constructed to calculate the fuzzy membership value of a given soil to the four HSGs based on hydrologic properties of the soil. The membership function should possess the following characteristics (Fig. 5): (1) maximum membership value of 1.0 is achieved at typical $K_{\text {MINsat }}$, (2) membership to one group decreases smoothly from 1.0 to 0.0 as $K_{\text {MINsat }}$ deviates from the group's typical value to that of the neighboring group, and (3) membership will be 0.5 at the bound of two neighboring groups.

The membership function proposed by Burrough (1989) was modified to fulfill the requirements mentioned above. Modifications are shown in Eqs. (6) and (7):

$\left\{\begin{array}{l}S_{i}=\frac{1}{1+\left|\frac{x-x_{i}}{x_{0.5}-x_{i}}\right|^{2}} \times\left|\frac{x-x_{j}}{x_{0.5}-x_{j}}\right|, \quad\left|x-x_{i}\right|<\left|x_{j}-x_{i}\right| \\ S_{i}=0, \quad\left|x-x_{i}\right|>\left|x_{j}-x_{i}\right|\end{array}\right.$

where $S_{i}=$ membership of a soil (with its $K_{\text {MINsat }}=x$ ) to hydrologic soil group " $i$ ", $x=K_{\text {MINsat }}$ of the soil, $x_{i}$ and $x_{j}$ is the typical $K_{\text {MINsat }}$ value of soil group " $i$ " and the neighboring soil group " $j$ ", respectively, and $x_{0.5}$ $=K_{\mathrm{MINsat}}$ value at the neighboring bound between group " $i$ " and group " $j "$.

If the sum of the soil memberships to all HSGs is not equal to 1.0 , the memberships will be standardized to a sum of 1 applying the equation:

$\left\{\begin{array}{l}S_{i}^{\prime}=S_{i} /\left(S_{i}+S_{j}\right) \\ S_{j}^{\prime}=S_{j} /\left(S_{i}+S_{j}\right)\end{array}\right.$ 
Table 1 The value and range of $K_{\text {MINsat }}$ for each HSG under a logarithmic coordinate

\begin{tabular}{|c|c|c|c|c|c|c|c|c|}
\hline \multirow{2}{*}{$\begin{array}{l}\text { Parameter } \\
\text { HSG }\end{array}$} & \multicolumn{4}{|c|}{$Z_{\text {imper }}^{\mathrm{a}}>100 \mathrm{~cm}$} & \multicolumn{4}{|c|}{$50 \mathrm{~cm}<Z_{\text {imper }}<100 \mathrm{~cm}$} \\
\hline & $\mathrm{D}$ & $\mathrm{C}$ & $\mathrm{B}$ & A & $\mathrm{D}$ & $\mathrm{C}$ & $\mathrm{B}$ & A \\
\hline Typical & $-0.14^{\mathrm{b}}$ & 0.66 & 1.36 & 1.76 & 0.26 & 1.06 & 1.86 & 2.26 \\
\hline Left width & / & 0.50 & 0.20 & 0.20 & / & 0.50 & 0.30 & 0.10 \\
\hline Right width & 0.30 & 0.50 & 0.20 & / & 0.30 & 0.50 & 0.30 & I \\
\hline Range & $<0.16$ & $0.16-1.16$ & $1.16-1.56$ & $>1.56$ & $<0.56$ & $0.56-1.56$ & $1.56-2.16$ & $>2.16$ \\
\hline
\end{tabular}

${ }^{a} Z_{\text {imper }}$ depth of the impermeable layer bellow soil surface (cm), "/" value not definite

b $K_{\text {MINsat }}$ under a logarithmic coordinate with a base of 10 , that is, [log 10$](\mathrm{mm} / \mathrm{h})$

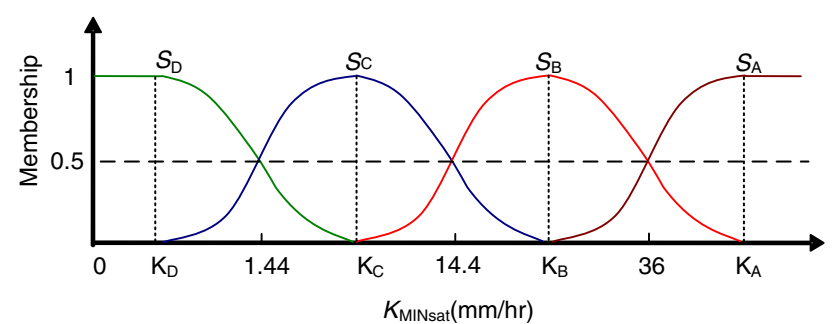

Fig. 5 Sketch of the membership curves. Depth to water impermeable layer $>100 \mathrm{~cm} . S_{\mathrm{A}}, S_{\mathrm{B}}, S_{\mathrm{C}}$, and $S_{\mathrm{D}}$-memberships for group A, $\mathrm{B}, \mathrm{C}$, and $\mathrm{D}$

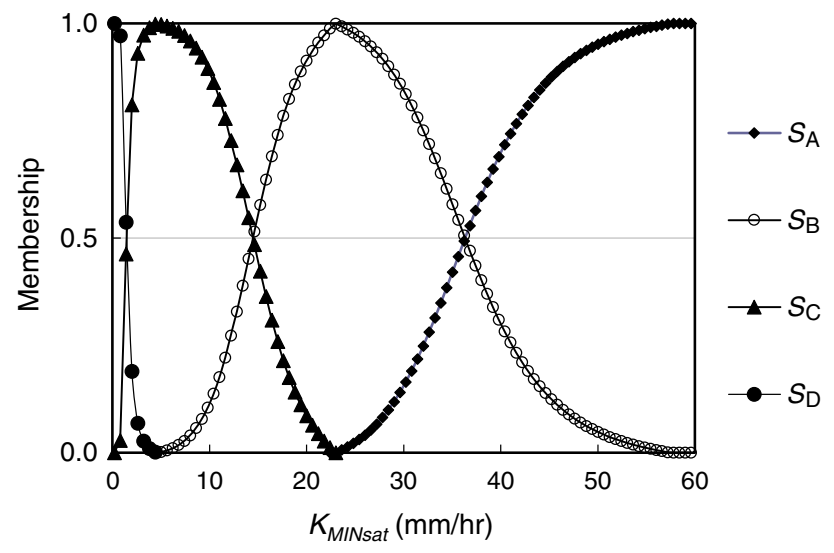

Fig. 6 Variation of fuzzy membership curves. Depth to water impermeable layer $>100 \mathrm{~cm}$

where $S_{i}$ and $S_{j}$ are memberships of the soil to group i and j before standardization, respectively, $S_{i}^{\prime}$ and $S_{j}^{\prime}$ are memberships after standardization.

The variation of fuzzy memberships with soil attributes, i.e., $K_{\text {MINsat, }}$ was calculated according to Eq. (6) and (7) (Fig. 6). Membership for each soil group changes smoothly from 1 to 0 , which exhibits the gradual transition of soil group from one to another in accordance with soil attributes variation. Neighboring membership curves intersect at 0.5 (Fig. 6). The shapes of membership curves for different soil groups are not exactly the same because of different ranges of $K_{\mathrm{MINsa}}$, e.g., ranges for group A and D may not be in the same order of magnitude. A soil with
$K_{\text {MINsat }}$ small or close to 0 general has high membership to group D and close to 1 ; with the increase of the $K_{\text {MINsat }}$, membership will alternatively increase to 1 in soil groups C, B, and A (Fig. 6). Finally, the fuzzy membership of a given soil to each soil group can be derived.

\section{Computing CN using fuzzy membership}

For a specific land cover, $\mathrm{CN}$ for the four HSGs $\left(\mathrm{CN}_{\mathrm{A}}\right.$, $\mathrm{CN}_{\mathrm{B}}, \mathrm{CN}_{\mathrm{C}}$, and $\mathrm{CN}_{\mathrm{D}}$ ) are defined. Based on the derived membership vector $S\left(S_{\mathrm{A}}, S_{\mathrm{B}}, S_{\mathrm{C}}\right.$, and $\left.S_{\mathrm{D}}\right)$ for a soil, a detailed $\mathrm{CN}$ (indicated as fuzzy $\mathrm{CN}$ ) could be calculated using a linear weighted function:

$\mathrm{CN}_{\text {fuzzy }}=\frac{\sum_{i=\mathrm{A}}^{\mathrm{D}} S_{i} \times \mathrm{CN}_{i}}{\sum_{i=\mathrm{A}}^{\mathrm{D}} S_{i}}$

where $\mathrm{CN}_{\text {fuzzy }}=$ fuzzy $\mathrm{CN}$ for a given soil at specific land cover condition, $S_{i}=$ membership of the soil to $\mathrm{HSG}_{i}$, $\mathrm{CN}_{i}=\mathrm{CN}$ for corresponding $\mathrm{HSG}_{i}(i=\mathrm{A}, \mathrm{B}, \mathrm{C}, \mathrm{D})$ defined in the look-up table.

\section{Development of an automation system}

To facilitate the application of the developed method, an automated fuzzy system coupling the existing CN2 tables and soil databases was developed. The proposed method was realized with Visual Basic language. Fuzzy CNs for a new area could be derived automatically once the soil database and land use data were provided.

The difference between a derived fuzzy $\mathrm{CN}$ and the original $\mathrm{CN}$ from $\mathrm{NEH}$ of a specific soil-cover complex is presented in Fig. 7. The four original $\mathrm{CN}$ values from $\mathrm{NEH}$ (CN_NEH) appear as descending "terraces" according to the increase of $K_{\text {MINsat, }}$ which are caused by the sudden shift of HSGs. Thus, CNs differ largely from each other if the soil is assigned to different HSGs, e.g., in the described case, $\mathrm{CN}$ difference between group A and group B would be up to 28. However, the fuzzy $\mathrm{CN}$ derived through fuzzy membership approach changes continuously and smoothly with $K_{\text {MINsat }}$. The proposed fuzzy membership approach enhances gradual $\mathrm{CN}$ change with soil properties variation, 


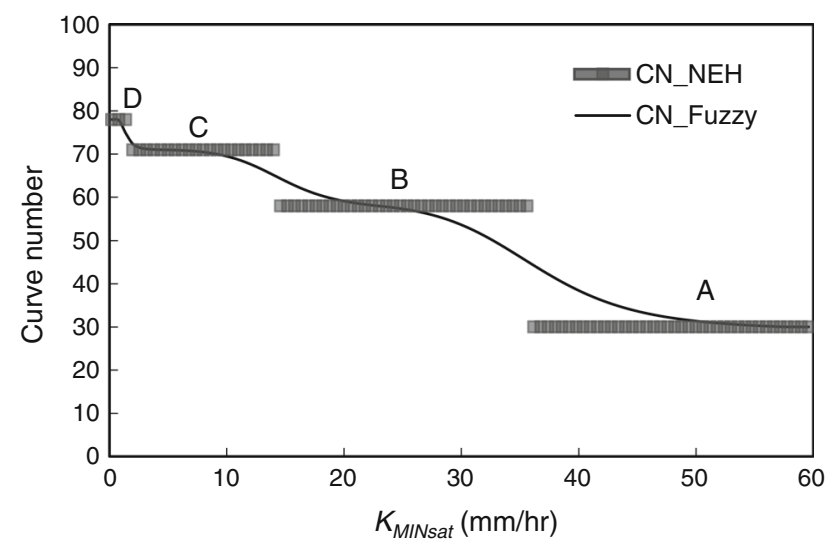

Fig. 7 Comparision of fuzzy CN (CN_Fuzzy) and the original CN (CN_NEH). (Depth to water impermeable layer $>100 \mathrm{~cm}$ )

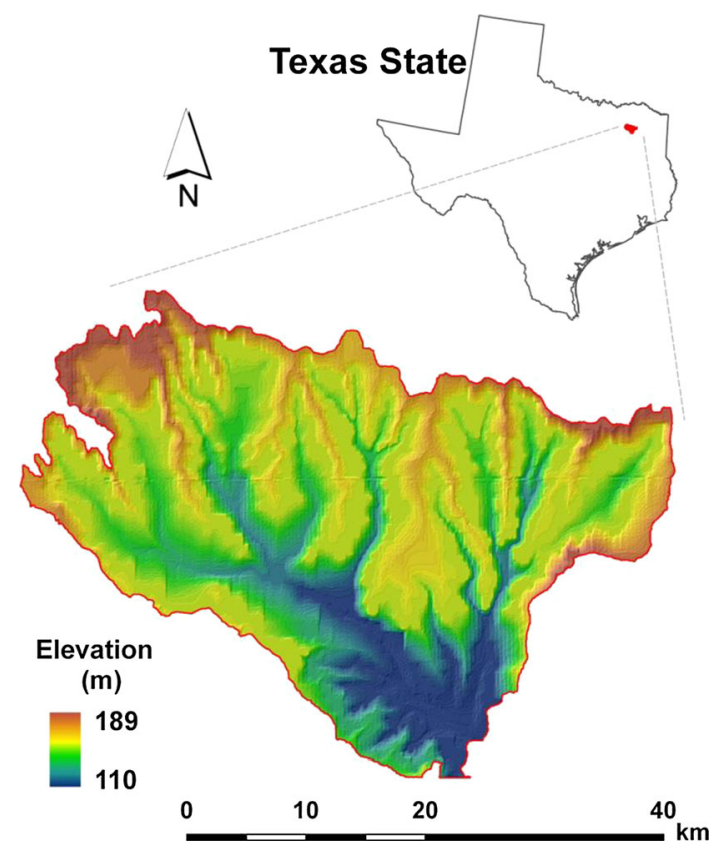

Fig. 8 Geographical setting and terrain of the Lake Fork watershed area (Texas, United States)

facilitating the fuzzy $\mathrm{CN}$ variation within a soil group and between neighboring groups.

\section{Case study and discussions}

Description of study site

The differences between $\mathrm{CN}$ derived from the fuzzy method and the traditional NEH method and the consequent hydrological effects have been examined in the Lake fork watershed. The Lake fork watershed $\left(1,219.8 \mathrm{~km}^{2}\right.$, with $111 \mathrm{~km}^{2}$ water surface area) is located at Texas state

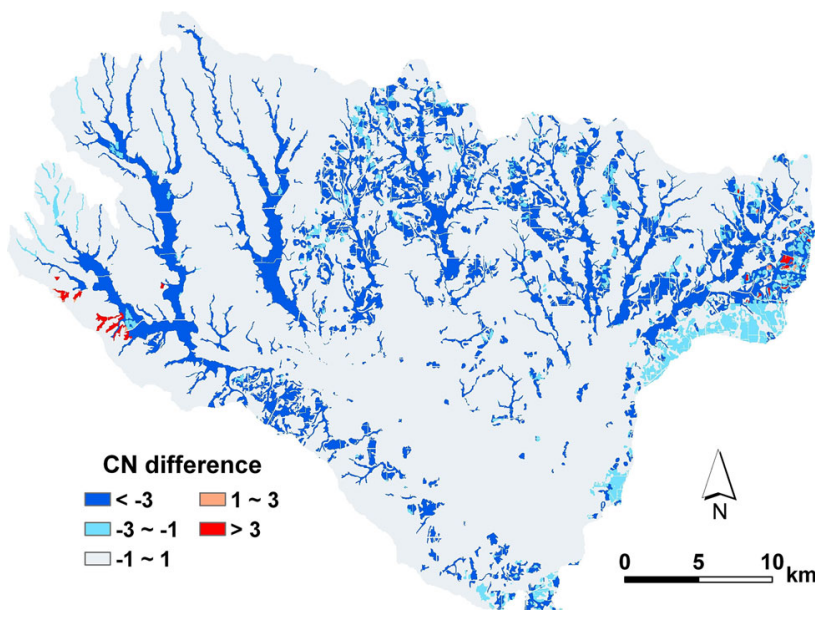

Fig. 9 Spatial differences between fuzzy CN2 and NEH CN2

of the United States (Fig. 8), and the Soil and Water Assessment Tool (SWAT) software package was applied and SCS-CN module in the model was adopted to simulate hydrologic process. Soil Survey Geographic database (SSURGO) at 1:24,000 and National Land Cover Database (NLCD) with a $30 \mathrm{~m}$ spatial resolution from US Geological Survey were used for derivation of spatially distributed CN for the watershed. CN2 was obtained using both the NEH method and the fuzzy method.

Analysis of the soil map reveals there are overall 67 soil types in the study area. All these soils are classified into four HSGs in the soil database. Finally, many soils are classified into the same HSG, for example, the number of soils contained in group A, B, C, and D is 4, 11,16 , and 36 , respectively. Therefore, it can be inferred that the aggregation effect of traditional HSG on soil information does exist as a large number of soils are assigned to the same HSG. Those soils assigned to the same HSG would have the same $\mathrm{CN}$ value if other conditions are the same, although their attributes vary from each other.

\section{Spatial differences of $\mathrm{CN}$}

The spatial distribution of $\mathrm{CN} 2$ was mapped separately for the proposed fuzzy $\mathrm{CN} 2$ and the traditional CN2 (NEH CN2). Spatial differences of $\mathrm{CN} 2$ between the two approaches were calculated by subtracting NEH CN2 map from fuzzy $\mathrm{CN} 2$ map using raster calculator tools in ESRI ArcGIS software.

CN2 differences are widely distributed in the study area, mostly concentrated at riparian areas (Fig. 9). About $21 \%$ of the area has CN2 difference while $18 \%$ of the area has a difference $>3.0$. These differences are mainly associated to soils not exactly at HSGs typical values, with varying fuzzy 
Table 2 Improper HSG assignment checked out by the fuzzy system

\begin{tabular}{|c|c|c|c|c|c|c|c|c|}
\hline Soil & Soil depth $(\mathrm{cm})$ & $D_{\text {Imper }}^{\mathrm{a}}(\mathrm{cm})$ & $D_{1}^{\mathrm{b}}(\mathrm{cm})$ & $K_{1}^{\mathrm{c}}(\mathrm{mm} / \mathrm{h})$ & $D_{2}(\mathrm{~cm})$ & $K_{2}(\mathrm{~mm} / \mathrm{hr})$ & HSG in SSURGO & HSG with largest membership \\
\hline A576058 & 203 & None & $0-33$ & 32.4 & $34-102$ & 32.4 & $\mathrm{C}$ & B \\
\hline
\end{tabular}

CN2. Most of the differences are negative, suggesting that the fuzzy CN2 is lower than NEH CN2 for the relating soils in the study area.

Large negative $\mathrm{CN}$ differences are mainly attributed to the soils close to the bound of neighboring HSGs. For example, soils of map unit A374401 (equivalent to soil name) $(9.3 \%$ of area), A374405 (6.2\% of area) and A374384 (2.0\% of area) are all assigned to HSG B according to NEH method. However, as their water impermeable layer depth $>100 \mathrm{~cm}$ and $K_{\text {MINsat }}=32.4$ $\mathrm{mm} / \mathrm{h}$, these soils are close to the boundary $(36 \mathrm{~mm} / \mathrm{h})$ between group A and group B. In the fuzzy system, these soils are associated to $\mathrm{CN}$ close to the average value of typical $\mathrm{CN}$ for group $\mathrm{A}$ and $\mathrm{B}$, which will be obviously smaller than the typical $\mathrm{CN}$ of group $\mathrm{B}$.

\section{Identification of improper HSG placement}

The developed automation system can also help identify improper HSG placement. It automatically calculates the fuzzy memberships of a soil to all HSGs; these four memberships (elements in the similarity vector) vary from 0 to 1 with HSG, and there must be one HSG possesses the largest membership among the four. Thus property of that soil is most similar to the HSG with the largest membership (Figs. 3, 5) Thus, the HSG corresponding to the maximum membership should be the one assigned during soil survey, supposing the manual classification during soil survey is correct. Therefore, the HSG with the maximum membership in the fuzzy system can be compared with the HSG recorded in the soil database to examine if there's any inconsistency. In case inconsistency occurred, such soil should be carefully checked to verify their classifications.

Inconsistent assignment of HSG checked out by the automation system is shown in Table 2. Soil map unit A576058 was assigned to group C in SSURGO database, but it has greatest similarity to group B based on the fuzzy system. The fuzzy system successfully detected this inconsistency in this experiment.

\section{Effect of fuzzy $\mathrm{CN}$ on runoff modeling}

According to SCS-CN model, differences of $\mathrm{CN}$ will promote simulated runoff differences in runoff modeling, especially for spatially distributed modeling. Thus, the increased capability of fuzzy $\mathrm{CN}$ in representing detailed soil information would be useful for distributed watershed modeling.

To examine the effect of fuzzy $\mathrm{CN}$ on runoff modeling, $\mathrm{CN}$ derived from the fuzzy approach and traditional methods was separately input into SWAT model for runoff modeling, given other conditions completely the same. Simulated runoff for 2 years (average precipitation $=$ about $1,229 \mathrm{~mm}$ ) is extracted and average yearly runoff differences based on the two $\mathrm{CN}$ approaches were calculated (Fig. 10). The runoff map shows a considerable different area and most of it is larger than $10 \mathrm{~mm}$. Meanwhile, relative runoff difference map (Fig. 10b) shows about $20 \%$ of the total area has runoff differences larger than $10 \%$. Comparing Fig. 10 with Fig. 9, it could be clearly observed that runoff differences were highly correlated with $\mathrm{CN}$ differences, and variation of $\mathrm{CN}$ would cause significant runoff differences (e.g., $>20 \%$ ).

The large differences between simulated runoff reveal that $\mathrm{CN}$ derived from different approaches significantly affects the spatial distribution of simulated runoff. As fuzzy $\mathrm{CN}$ is conceptually reasonable and technically available, it is helpful to derive detailed $\mathrm{CN}$ for further use in distributed runoff modeling.

\section{Conclusions}

The traditional process of generalizing soil types into four HSGs during curve number acquisition induces significant aggregation of detailed information which would be important in watershed modeling. This study proposed a fuzzy HSG concept and developed an automated system to obtain continuous relationship between $\mathrm{CN}$ and soil properties.

The proposed method was applied and verified in a case study in the United States, with the effects of the fuzzy CN on runoff modeling also evaluated. The obtained results indicated that the fuzzy system had the potential to check improper HSG classifications, reduce soil information aggregation, increase spatial detail of $\mathrm{CN}$ and affect the simulated runoff. In addition, such an automated system 

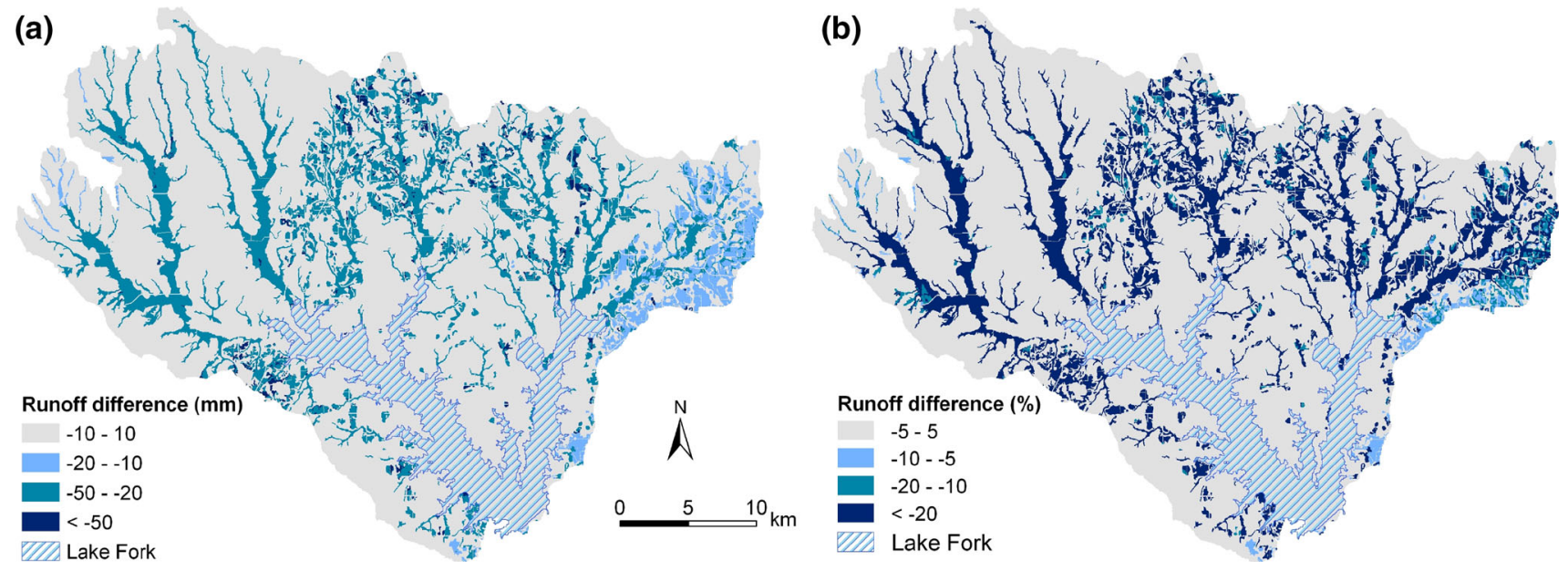

Fig. 10 Differences of simulated yearly average runoff based on different $\mathrm{CN}$ maps. a runoff difference depth (mm); $\mathbf{b}$ relative runoff difference $(\%)$

will also facilitate consistent assignment of hydrologic groups in the future by adopting the same standard in different places or by different organizations.

\begin{abstract}
Acknowledgments The authors appreciated very much the anonymous reviewers for their valuable instructive comments in revising the manuscript. We thank Mingsi Xie from Research Laboratory for Conservation and Archaeology of Shanghai Museum who contributed discussions and help improve the language. This study is supported by the Key Research Program of Chinese Academy of Sciences (Grant No. KZZD-EW-13), National Water Pollution Control and Management Technology Major Project (2013ZX07103006-005), National Natural Science Foundation of China (Project No. 41201038 and 41023010), and is also supported by Chinese Academy of Sciences visiting professorship for senior international scientists (Grant No. 2012T1Z0039).
\end{abstract}

\section{References}

Burrough PA (1989) Fuzzy mathematical methods for soil survey and land evaluation. Eur J Soil Sci 40:477-492

Elhakeem M, Papanicolaou A (2009) Estimation of the runoff curve number via direct rainfall simulator measurements in the state of Iowa, USA. Water Resour Manag 23(12):2455-2473

Hjelmfelt AT, Woodward DA, Conaway G, Quan QD, Mullem JV, Hawkins RH (2001) Curve Numbers, Recent Developments. In: Proceedings of the 29th IAHR Congress, Beijing, China. pp 285-291

Li RK, Zhu AX, Song XF, Li BL, Pei T, Qin CZ (2012) Effects of spatial aggregation of soil spatial information on watershed hydrological modelling. Hydrol Process 26(9):1390-1404

Mark DM, Csillag F (1989) The nature of boundaries on 'area-class' maps. Cartographica 26(1):65-78

McCuen RH (2004) Hydrologic analysis and design, 3rd edn. Prentice Hall, Upper Saddle River

Mishra S, Sahu R, Eldho T, Jain M (2006) An improved ia-s relation incorporating antecedent moisture in SCS-CN methodology. Water Resour Manag 20(5):643-660
Mishra S, Jain M, Suresh Babu P, Venugopal K, Kaliappan S (2008) Comparison of AMC-dependent CN-conversion formulae. Water Resour Manag 22(10):1409-1420

Musgrave GW (1955) How much of the rain enters the soil? US Department of Agriculture, Yearbook of Agriculture: Water. US Govt. Printing Office, Washington, DC, pp 151-159

Nielson RD, Hjelmfelt AT (1998) Hydrologic soil-group assignment. In: Abt SR, Young-Pezeshk J, Watson CC (eds) Water Resource Engineering 98. In: Proceedings of the International Water Resources Engineering Conference. American Society of Civil Engineers, Reston, Virginia, pp 1297-1302

Ponce VM, Hawkins RH (1996) Runoff curve number: has it reached maturity? J Hydrol Eng 1(1):11-19

Schaap MG, Leij FJ, van Genuchten MT (2001) ROSETTA: a computer program for estimating soil hydraulic parameters with hierarchical pedotransfer functions. J Hydrol 251(3-4):163-176

Shirmohammadi A, Yoon KS, Rawls WJ, Smith OH (1997) Evaluation of curve number procedures to predict runoff in GLEAMS. J Am Water Resour Assoc 33(5):1069-1076

Soil Conservation Service (1972) National Engineering Handbook. Section 4: Hydrology. Soil Conservation Service, Washington, DC

Soil Survey Division Staff (1993) Soil survey manual. Soil Conservation Service, Washington

USDA (2004) National Engineering Handbook, 210-VI. Part 630, chapter 9, Hydrologic Soil-Cover Complexes. Natural Resources Conservation Service, Washington, DC

USDA (2007) National Engineering Handbook, title 210-VI. Part 630, chapter 7, Hydrologic Soil Groups. Natural Resources Conservation Service, Washington, DC

Van Mullem JA (1991) Runoff and peak discharges using green-ampt infiltration model. J Hydrol Eng 117(3):354-370

Van Mullem JA, Woodward DE, Hawkins RH, Hjelmfelt AT Jr (2002) Runoff curve number method: beyond the handbook. Second Federal Interagency Hydrologic Modeling Conference, Las Vegas, Nevada

Ye XC, Zhang Q, Viney NR (2011) The effect of soil data resolution on hydrological processes modelling in a large humid watershed. Hydrol Process 25(1):130-140

Young DF, Carleton JN (2006) Implementation of a probabilistic curve number method in the PRZM runoff model. Environ Model Softw 21:1172-1179 
Zhai H, Benson C (2006) The log-normal distribution for hydraulic conductivity of compacted clays: two or three parameters? Geotech Geol Eng 24(5):1149-1162

Zhu AX (1997) A similarity model for representing soil spatial information. Geoderma 77:217-242

Zhu AX, Band L, Vertessy R, Dutton B (1997) Derivation of soil properties using a soil land inference model (SoLIM). Soil Sci Soc Am J 61(2):523-533
Zhu AX, Hudson B, Burt JE, Lubich K, Simonson D (2001) Soil mapping using GIS, expert knowledge, and fuzzy logic. Soil Sci Soc Am J 65(5):1463-1472 